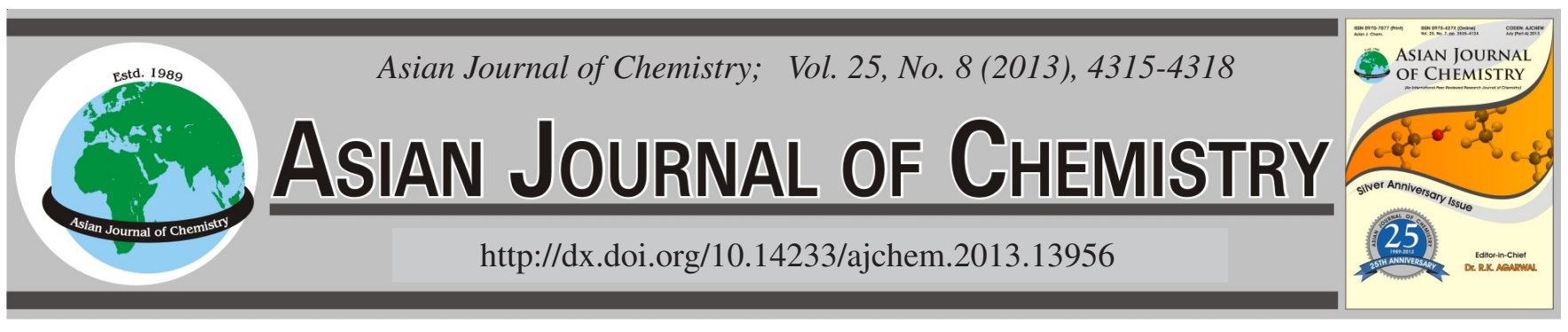

\title{
Hierarchical Structures of $\mathrm{Li}_{1+\mathrm{x}} \mathrm{V}_{3} \mathrm{O}_{8}$ Nanorods Growing on Electrospun Fibers: Synthesis, Characterization and Electrochemical Properties
}

Bin Yan, Shuping Wang, HongXiao Yang, Lijun Feng, Huiying Wei and Yanzhao Yang*

Key Laboratory for Special Functional Aggregate Materials of Education Ministry, School of Chemistry and Chemical Engineering, Shandong University, Jinan 250100, P.R. China

*Corresponding author: Fax: +86 531 88564464; Tel: +86 531 88365431; E-mail: yzhyang@ @du.edu.cn

(Received: 24 April 2012;

Accepted: 9 February 2013)

AJC-12953

\begin{abstract}
Hierarchical structures of $\mathrm{Li}_{1+\mathrm{x}} \mathrm{V}_{3} \mathrm{O}_{8}$ nanorods growing on electrospun fibers have been successfully synthesized by electrospinning and calcinations. Field-emission scanning electron microscopy, transmission electron microscopy, X-ray diffraction and Raman spectra are applied to characterize the products. The formation mechanism of the hierarchical structures is investigated, showing that the morphology of the hierarchical structures is mainly determined by calcined conditions, such as temperature and time of calcination. Electrochemical properties of the $\mathrm{Li}_{1+\mathrm{x}} \mathrm{V}_{3} \mathrm{O}_{8}$ hierarchical structures are investigated by cyclic voltammetry and charge-discharge experiments. The results demonstrate that the $\mathrm{Li}_{1+\mathrm{x}} \mathrm{V}_{3} \mathrm{O}_{8}$ hierarchical structures exhibited a high discharge capacity $\left(313 \mathrm{mAhg}^{-1}\right)$ and excellent cycling stability.
\end{abstract}

Key Words: Hierarchical nanostructures, Lithium vanadate, Electrospinning, Cathode materials.

\section{INTRODUCTION}

In recent years, the controllable arrangement of microand nano-structured building blocks into hierarchical structures has attracted considerable interest to chemists and materials scientists ${ }^{1,2}$ because the properties of nano- and microcrystals depend not only on their chemical composition, but also on their structure, phase, shape and size. Such complex architectures, especially those based on one-dimensional nanostructures, are expected to display novel properties and may have potential applications in many fields such as catalysis, cosmetic, battery and medicine ${ }^{3}$. Many efforts have been put on the fabricating these architectures and a number of different approaches such as chemical vapor deposition ${ }^{4}$, laser-assisted catalytic growth ${ }^{5}$, template-based design techniques ${ }^{6}$ and solution-based selfassembly routes ${ }^{7}$ have been developed.

As a simple and versatile technique for generating ultra thin fibers, electrospinning was further extended to fabricate complex nanostructures with controllable hierarchical architectures ${ }^{8-12}$. For example, a novel hierarchical structure of $\mathrm{V}_{2} \mathrm{O}_{5}$ nanorods on $\mathrm{TiO}_{2}$ nanofibers was made by electrospinning ${ }^{13}$, nanofibers with hollow, core-shell or porous structures have also been synthesized through modifying electrospinning setup or adjusting the spinning parameters ${ }^{14,15} \cdot \mathrm{Li}_{1+\mathrm{x}} \mathrm{V}_{3} \mathrm{O}_{8}$ is one of the promising cathode materials in rechargeable lithium batteries, have been extensively studied due to attractive characteristics such as high specific capacity, good rate capacity and long cycle life ${ }^{16,17}$. But, no attempts have been made so far to prepare hierarchical structures of $\mathrm{Li}_{1+\mathrm{x}} \mathrm{V}_{3} \mathrm{O}_{8}$ nanorods growing on electrospun fibers for attaining good performance. In this report, hierarchical structures of $\mathrm{Li}_{1+\mathrm{x}} \mathrm{V}_{3} \mathrm{O}_{8}$ nanorods growing on electrospun fibers were fabricated through electrospinning and calcinations. The electrochemical properties of the asprepared $\mathrm{Li}_{1+\mathrm{x}} \mathrm{V}_{3} \mathrm{O}_{8}$ hierarchical architectures were investigated and the results exhibited the $\mathrm{Li}_{1+\mathrm{x}} \mathrm{V}_{3} \mathrm{O}_{8}$ hierarchical architecture with high capacities and excellent cycling reversibility, which indicates their promising features for applications as electrode materials in advanced rechargeable lithium ion batteries.

\section{EXPERIMENTAL}

Preparation of $\mathrm{Li}_{1+\mathrm{x}} \mathrm{V}_{3} \mathrm{O}_{\mathbf{8}}$ fibers: All chemicals were of analytical grade and were used as received without further purification. Sol-gel method was used to prepare the electrospinning solution. In a typical experiment, $0.0105 \mathrm{~mol}$ lithium acetate monohydrate and 0.04 mol citric acid were dissolved in $50 \mathrm{~mL}$ distilled water and $0.03 \mathrm{~mol} \mathrm{NH}_{4} \mathrm{VO}_{3}$ was added into $80 \mathrm{~mL}$ distilled water. Then the former solution was added to the $\mathrm{NH}_{4} \mathrm{VO}_{3}$ under stirring and $\mathrm{NH}_{4} \mathrm{VO}_{3}$ began to dissolve slowly with the addition of citric acid until it got salmon pink solution. The colour of the solution became deeper during the stirring process and turned to navy blue finally. Then the mixture was kept at $70{ }^{\circ} \mathrm{C}$ to turn into a viscous sol to form a sol with viscosity of 3.0 Pa.S. The sol was then loaded into a Teflon bushing equipped with a spinneret made of 
stainless steel (the aperture is $400 \mathrm{~mm}$ ), which was connected to a high-voltage supply (BGG-80 kV/20 mA). When the intensity of electric field was high enough, a charged sol jet was ejected from the spinneret to form a fiber-like product that fell on the collector and was then dried to remove volatile components. The obtained xerogel fibers were first heated at $400{ }^{\circ} \mathrm{C}$ for $2 \mathrm{~h}$ in air with a heating rate of $0.5^{\circ} \mathrm{C} \min ^{-1}$ and then heated at $550^{\circ} \mathrm{C}$ for $8 \mathrm{~h}$ at the heating rate of $2.0^{\circ} \mathrm{C} \mathrm{min}{ }^{-1}$ from 400 to $550^{\circ} \mathrm{C}$.

The morphology of fibers was investigated by a JEOL JSM-6700F field-emission scanning electron microscopy (FESEM Hitachi S-520) and transmission electron microscopy (TEM, model H-800). X-ray diffraction patterns of product were examined using a Rigaku D/Max 2200 PC diffractometer with a graphite monochromator and $\mathrm{CuK}_{\alpha}$ radiation $(\lambda=$ $0.15418 \mathrm{~nm}$ ) while the voltage and electric current were held at $40 \mathrm{kV}$ and $20 \mathrm{~mA}\left(2 \theta=10 \sim 80^{\circ}\right)$. Raman spectra were collected at room temperature using a Jobin-Yvon ISA U1000 Raman spectrometer in a quasi-backscattering configuration, the wavelength of the Ar laser was $514.5 \mathrm{~nm}$. BET surface area was performed on SSA-3500 micromeritics using the $\mathrm{N}_{2}$ adsorption-desorption method.

Electrochemical properties of the $\mathrm{Li}_{1+\mathrm{x}} \mathrm{V}_{3} \mathrm{O}_{8}$ hierarchical structures: Electrochemical measurements were carried out using laboratory cells. The fiber electrode was fabricated by loading the fibers into a bag made up of a stainless steel net and they were subjected to a pressure of 12.0 MPa. Fresh lithium foil was used as reference and counter electrodes. The electrolyte consisted of $1 \mathrm{M} \mathrm{LiPF}_{6}$ in a non-aqueous solution of ethylene carbonate and dimethyl carbonate at a volume ratio of 1:1. Cyclic voltammograms were obtained at a scanning rate of $0.1 \mathrm{mV} \mathrm{s}^{-1}$ between 0.01 and $3.0 \mathrm{~V}$. Charge/discharge characteristics of the cells were recorded at a current density of $50 \mathrm{mAg}^{-1}$.

\section{RESULTS AND DISCUSSION}

The phase composition and purity of the products were characterized by XRD analysis. Fig. 1a illustrates the XRD patterns of of the $\mathrm{Li}_{1+\mathrm{x}} \mathrm{V}_{3} \mathrm{O}_{8}$ hierarchical structures. All of the diffraction peaks of XRD pattern of the $\mathrm{Li}_{1+\mathrm{x}} \mathrm{V}_{3} \mathrm{O}_{8}$ hierarchical structures could be well indexed to the monoclinic structure with the unit cell parameters of $\mathrm{a}=6.680 \AA, \mathrm{b}=3.595 \AA$, $\mathrm{c}=$ $12.036 \AA$, which was in agreement with the layered $\mathrm{Li}_{1+\mathrm{x}} \mathrm{V}_{3} \mathrm{O}_{8}$ (JCPDS file No.72-1193). The Raman spectrum of hierarchical structures was shown in Fig. 1b. The characteristic adsorption of $\mathrm{Li}_{1+\mathrm{x}} \mathrm{V}_{3} \mathrm{O}_{8}$ hierarchical structures at $987 \mathrm{~cm}^{-1}$ were assigned to the two vanadyl bonds in $\mathrm{VO}_{6}$ while the band at $767 \mathrm{~cm}^{-1}$ was attributed to the atomic motion of corner-sharing oxygen among the $\mathrm{VO}_{6}, \mathrm{VO}_{5}$ and $\mathrm{LiO}_{6}$ poyhedrons ${ }^{18}$.

Fig. 2 provides the direct information of microstructures and morphologies of the $\mathrm{Li}_{1+\mathrm{x}} \mathrm{V}_{3} \mathrm{O}_{8}$ hierarchical structures at low and high magnifications, respectively. The low magnification (Fig. 2a) FE-SEM image revealed that the products consisted of a large quantity of 3-D hierarchical structures with a major core structure and secondary rods grown on the surfaces of the $\mathrm{Li}_{1+\mathrm{x}} \mathrm{V}_{3} \mathrm{O}_{8}$ fibers. As shown in Fig. 2b, the length of major core fibers along the axis could be as long as tens of micrometers and the diameter was about 1-2 $\mu \mathrm{m}$, whereas the length of the secondary nanorods growing on the major core fibers was in the range of 1-5 $\mu \mathrm{m}$, with diameters ranging from 100 to $300 \mathrm{~nm}$. The fibers were placed in deionized water and treated ultrasonicly. The corresponding SAED pattern (Fig. 2c) of the nanorod indicated a preferential growth [010] of the nanorod.

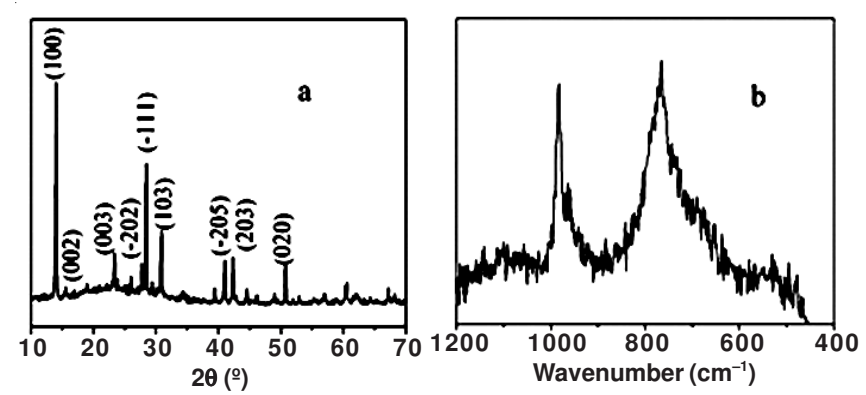

Fig. 1. XRD pattern (a) and Raman spectrum (b) of $\mathrm{Li}_{1+\mathrm{x}} \mathrm{V}_{3} \mathrm{O}_{8}$ hierarchical structures

To shed light on the formation mechanism of novel $\mathrm{Li}_{1+\mathrm{x}} \mathrm{V}_{3} \mathrm{O}_{8}$ hierarchical structures, we tracked the evolution of their growth process by examining the products harvested at different intervals of calcined times. The resulting morphology was dependent on calcined conditions. The obvious evolutionary stages could be clearly observed and were shown in Fig. 3. The gel fibers were calcined at $550{ }^{\circ} \mathrm{C}$ in air for $4 \mathrm{~h}$, only simple $\mathrm{Li}_{1+\mathrm{x}} \mathrm{V}_{3} \mathrm{O}_{8}$ fibers could be obtained (Fig. 3a). As the calcinations proceeded, however, new features started to evolve on the surface of the fibers. After the as-spun fibers have been calcined for $6 \mathrm{~h}$, the surface of the fibers became rough and

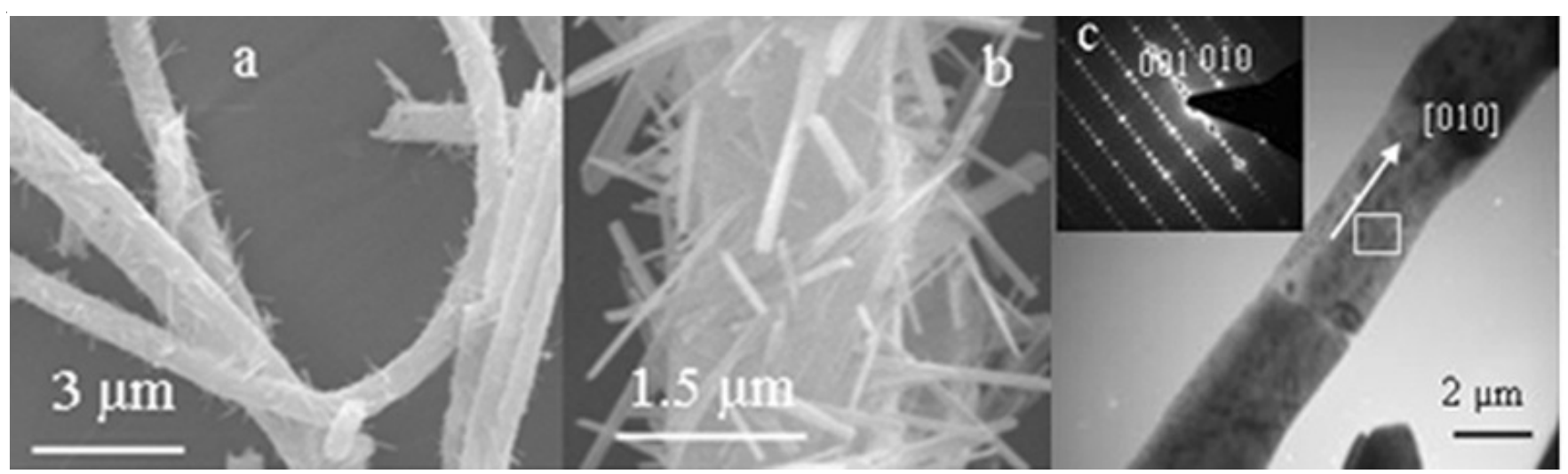

Fig. 2. (a) low-magnification, (b) high-magnification FE-SEM images and (c) selective area electron diffraction of $\mathrm{Li}_{1+\mathrm{x}} \mathrm{V}_{3} \mathrm{O}_{8}$ hierarchical structures 


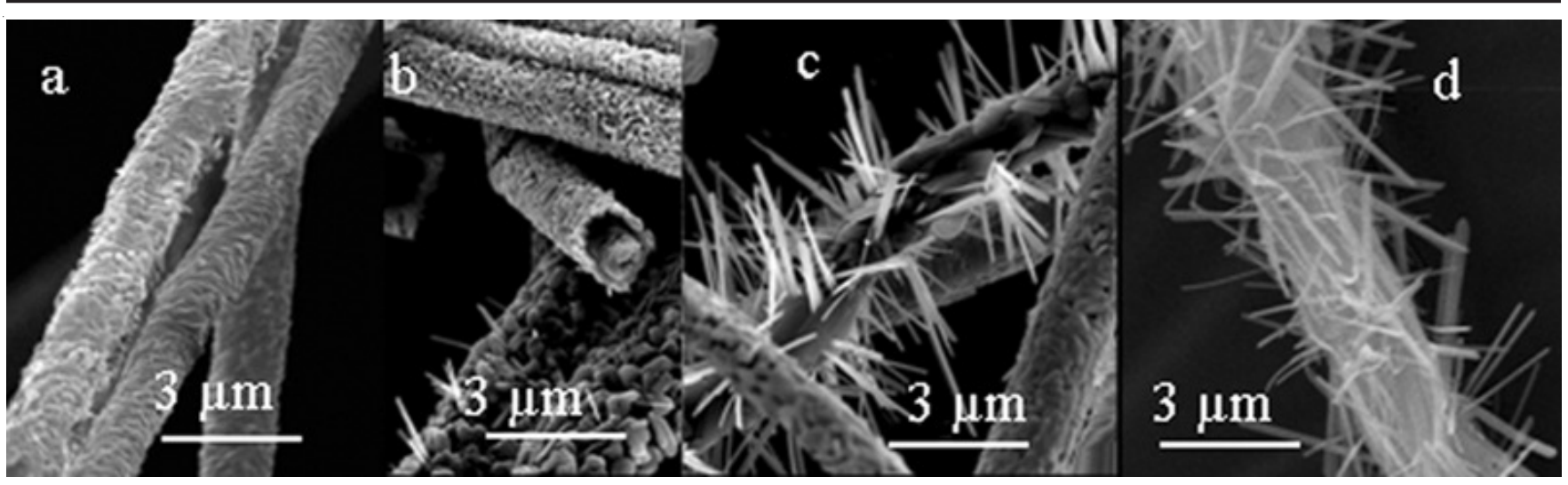

Fig. 3. FE-SEM images of $\mathrm{Li}_{1+\mathrm{x}} \mathrm{V}_{3} \mathrm{O}_{8}$ hierarchical structures after calcined at $550{ }^{\circ} \mathrm{C}$ for (a) $4 \mathrm{~h}$, (b) $5 \mathrm{~h}$, (c) $6 \mathrm{~h}$ and (d) $8 \mathrm{~h}$

short nanorods with a smooth surface appeared on the fibers. The surface of the fibers became rougher and the number of nanorods increased as prolongeing the time of calcination. The growth of nanorods was fast at the beginning of calcination, slowed after about $1 \mathrm{~h}$ and finally stopped after several hours. Temperature-dependent experiments indicated that the calcination temperature also significantly affected the formation of the $\mathrm{Li}_{1+x} \mathrm{~V}_{3} \mathrm{O}_{8}$ hierarchical structures. It demonstrated that when the sample was calcined below $550{ }^{\circ} \mathrm{C}$, only simple $\mathrm{Li}_{1+\mathrm{x}} \mathrm{V}_{3} \mathrm{O}_{8}$ fibers could be formed. With the calcined temperature rising to $580{ }^{\circ} \mathrm{C}$, the rods composing the fibers grew further. When the fibers were sintered at $600{ }^{\circ} \mathrm{C}$, the fibers fused and could not keep the fiber morphology. On the basis of the above experimental results, we proposed the growth of $\mathrm{Li}_{1+\mathrm{x}} \mathrm{V}_{3} \mathrm{O}_{8}$ hierarchical structures was controlled by thermodynamics through increasing the reaction temperature and prolonging the reaction time. $\mathrm{Li}_{1+\mathrm{x}} \mathrm{V}_{3} \mathrm{O}_{8}$ is monoclinic structure and belongs to the $\mathrm{P} 2_{1} / \mathrm{m}$ space group, which is composed of two basic structural units including a $\mathrm{VO}_{6}$ octahedron and a $\mathrm{VO}_{5}$ distorted trigonal bipyramids ${ }^{19}$. According to previous reports ${ }^{18-20}$, the $\mathrm{Li}_{1+\mathrm{x}} \mathrm{V}_{3} \mathrm{O}_{8}$ particles are preferential to form the nanorods at higher temperature due to its structure. Because of the confinement of the particles composed of the fibers, the growth of particles is always interfered by others, leading to that the calcined fibers are mostly composed of sheet-like particles. However, there are always some of particles, especially particle in the fiber surface, have enough area to make their growth be capable to expand spatially. Therefore, the nanorods with a smooth surface appeared on the fibers in the process of caicinations. Finally, the 3-D hierarchical structures with a major core structure and secondary rods growing on the site surfaces of the $\mathrm{Li}_{1+\mathrm{x}} \mathrm{V}_{3} \mathrm{O}_{8}$ fibers were formed.

Typical cyclic voltammograms of the $\mathrm{Li}_{1+\mathrm{x}} \mathrm{V}_{3} \mathrm{O}_{8}$ hierarchical structures were shown in Fig. 4a. The main cathodic peaks and one anodic peak were observed in the cyclic voltammogram curve, which indicated the complicated multistep lithium intercalation processes. Compared to the first cyclic voltammogram curve, the second cyclic voltammogram curve displayed a large decrease of the peak intensity. After the 3 th cycle, the area and shape of the cyclic voltammogram curves for $\mathrm{Li}_{1+\mathrm{x}} \mathrm{V}_{3} \mathrm{O}_{8}$ hierarchical structures exhibited very small changes, which indicated that the lithium-ion intercalation and de-intercalation became easier due to the fully wetting of the electrode and should support good cyclic stability. Charge-discharge experiments were carried out to investigate the electrochemical properties of the $\mathrm{Li}_{1+\mathrm{x}} \mathrm{V}_{3} \mathrm{O}_{8}$ products and the charge-discharge curve was given in Fig. 4b. In the first cycle, $\mathrm{Li}_{1+\mathrm{x}} \mathrm{V}_{3} \mathrm{O}_{8}$ hierarchical structures delivered highly initial discharge capacity of $c a .313 \mathrm{mAhg}^{-1}$, the capacity decreased to $c a .246 \mathrm{mAhg}^{-1}$ after 40 cycles. The hierarchical structures of $\mathrm{Li}_{1+\mathrm{x}} \mathrm{V}_{3} \mathrm{O}_{8}$ products had high BET surface area of $8.54 \mathrm{~m}^{2} \mathrm{~g}^{-1}$, which led to a short diffusion distance of the $\mathrm{Li}^{+}$ cations and was benefical to the intercalation/deintercalation of $\mathrm{Li}^{+}$cations ${ }^{21,22}$. On the other hand, the hierarchical structures of $\mathrm{Li}_{1+\mathrm{x}} \mathrm{V}_{3} \mathrm{O}_{8}$ products might offer a continuous electronic pathway, yielding an electronic conductivity of reasonable magnitude for Lithium batteries, in which the geometry of the fibers maximizes the solid-solution interfacial contact and results in increased charging rates. Therefore, the fiber materials presented high charge-discharge capacities and better cycle performance.
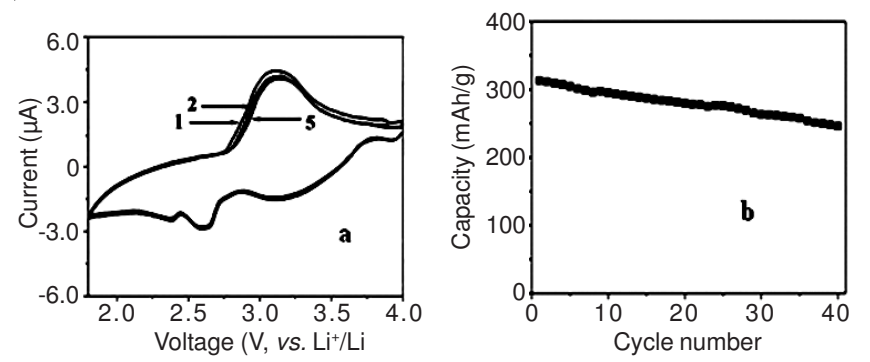

Fig. 4. Cyclic voltammograms and variation of discharge capacity as a function of cycle number using the $\mathrm{Li}_{1+\mathrm{x}} \mathrm{V}_{3} \mathrm{O}_{8}$ hierarchical structures.

\section{Conclusion}

3D hierarchical structures with a major core structure and secondary rods growing on the site surfaces of the $\mathrm{Li}_{1+\mathrm{x}} \mathrm{V}_{3} \mathrm{O}_{8}$ fibers were fabricated by using a single spinneret electrospinning technique combined with sol-gel method. The growth of $\mathrm{Li}_{1+\mathrm{x}} \mathrm{V}_{3} \mathrm{O}_{8}$ hierarchical structures was controlled by thermodynamics through controlling the reaction temperature and adjusting the reaction time. As electrode materials, the $\mathrm{Li}_{1+\mathrm{x}} \mathrm{V}_{3} \mathrm{O}_{8}$ hierarchical structures exhibited a high discharge and a good electrochemical performance. Therefore, the $\mathrm{Li}_{1+\mathrm{x}} \mathrm{V}_{3} \mathrm{O}_{8}$ hierarchical structures could be a promising model system as cathode materials in lithium-ion batteries. 


\section{ACKNOWLEDGEMENTS}

The authors acknowledged the financial support for this work from the National Natural Science Foundation of China (No. 21076115), the Major State Basic Research Development Program of China (No. 2011CB935901).

\section{REFERENCES}

1. L.J. Lauhon, M.S. Gudiksen, C.L. Wang and C.M. Lieber, Nature, 420 57 (2002).

2. Z. Yao, X. Zhu, C. Wu, X. Zhang and Y. Xie, Cryst. Growth Design, 7 , 1256 (2007).

3. Y. Li, J. Liu, X. Huang and G. Li, Cryst. Growth Design, 7, 1350 (2007).

4. A.C. Chen, X.S. Peng, K. Koczkur and B. Miller, Chem. Commun., 17, 1964 (2004).

5. A.M. Morales and C.M. Lieber, Science, 279, 208 (1998)

6. X.F. Duan and C.M. Lieber, Adv. Mater, 12, 298 (2000).

7. Y. Li, D. Xu, Q. Zhang, D. Chen, F. Huang, Y. Xu, G. Guo and Z. Gu, Chem. Mater, 11, 3433 (1999).

8. G. Cheng, J. Wang, X. Liu and K. Huang, J. Phys. Chem. B, 110, 16208 (2006).
9. Z. Liu, D.D. Sun, P. Guo and J.O. Leckie, Nano Lett., 7, 1081 (2007).

10. D. Li, J.T. McCann and Y. Xia, Small, 1, 83 (2005).

11. D. Li, Y. Wang and Y. Xia, Adv. Mater., 16, 361 (2004).

12. D. Li, G. Ouyang, J.T. McCann and Y. Xia, Nano Lett., 5, 913 (2005).

13. R. Ostermann, D. Li, Y. Yin, J.T. McCann and Y. Xia, Nano Lett., 6, 1297 (2006).

14. D. Li and Y. Xia, Nano Lett., 4, 933 (2004).

15. J.T. McCann, D. Li and Y. Xia, J. Mater. Chem., 15, 735 (2005).

16. F. Bonino, S. Panero, M. Pasquali and G. Pistoia, J. Power Source, 56, 193 (1995).

17. H. Xu, H. Wang, Z. Song, Y. Wang, H. Yan and M. Yoshimura, Electrochim. Acta, 49, 349 (2004).

18. G. Yang, G. Wang and W. Hou, J. Phys. Chem. B, 109, 11186 (2005).

19. S. Jounaneau, A.L. La Salle, A. Verbaere, M. Deschamps, S. Lascaud and D. Guyomard, J. Mater. Chem., 13, 921 (2003).

20. Y. Gu and F. Jian, J. Sol-gel. Sci. Technol., 46, 161 (2008).

21. S. Zhang, W. Li, C. Li and J. Chen, J. Phys. Chem. B, 110, 24855 (2006).

22. B. Li, G. Rong, Y. Xie, L. Huang and C. Feng, Inorg. Chem., 45, 64040 (2006). 